\title{
Tsunami Impacts on Nuclear Power Plants along Western Coast of India Due to a Great Makran Earthquake: A Numerical Simulation Approach
}

\author{
Mohd Zuhair*, Shahnawaz Alam \\ Department of Geology and Geophysics, Indian Institute of Technology, Kharagpur, India \\ Email: ${ }^{\star}$ zuhair.alig31@gmail.com
}

How to cite this paper: Zuhair, M. and Alam, S. (2017) Tsunami Impacts on Nuclear Power Plants along Western Coast of India Due to a Great Makran Earthquake: A Numerical Simulation Approach. International Journal of Geosciences, 8, 1417-1426. https://doi.org/10.4236/ijg.2017.812083

Received: October 10, 2017

Accepted: December 12, 2017

Published: December 15, 2017

Copyright ( 92017 by authors and Scientific Research Publishing Inc. This work is licensed under the Creative Commons Attribution International License (CC BY 4.0).

http://creativecommons.org/licenses/by/4.0/ (c) (i) Open Access

\begin{abstract}
The major seismicity source in the northern Arabian Sea is the Makran Subduction Zone (MSZ) that defines the tectonic boundary between the Arabian plate and the Eurasian plate, located offshore Iran and Pakistan over which an instrumentally registered earthquake $\left(\mathrm{M}_{\mathrm{w}} 8.1\right)$ generated a tsunami on 27 November, 1945. It has caused severe cataclysm to a vulnerable population along the surrounding coastlines, including India. It has been on a long seismic quiescence since this last event. The population and industrialization have exponentially increased along the coastal areas in last half decade. The highly exposed coastal locations to the tsunamis are the areas where the nuclear power plants are located. In the present work, a numerical simulation of a great tsunamigenic earthquake $(M 9)$ is presented that predicts the generation, propagation, run-up and travel time using TUNAMI N2 for estimating tsunami impacts along the nuclear power plants of the western coast of India. TUNAMI N2 code was designed for shallow water wave equations, which uses the finite-difference method based on staggered-leap frog scheme. Thus, it has potential to simulate a far-field tsunami with much more accuracy than other methods. It is observed that the tsunami will strike along the coast of Jaitapur Nuclear Power Plant (Maharashtra), Tarapur Nuclear Power Plant (Maharashtra), Kaiga Nuclear Power Plant (Karnataka) and Mithi-Virdi Nuclear Power Plant (Gujarat) after 210, 215, 225 and 230 minutes, respectively. Results show that the tsunami run-up is highest for Jaitapur coast $(2.32 \mathrm{~m})$. The Mithi-Virdi coast is the least effected $(0.93 \mathrm{~m})$ while Kaiga $(2.15 \mathrm{~m})$ and Tarapur coast $(2.12 \mathrm{~m})$ might have faced quite intense tsunami consequences. The arrival times and run-ups of the tsunami along the coast of different power plants have been calculated since these parameters are of vital impor-
\end{abstract}


tance in mitigation of the coastal hazard, evacuation planning and installation of early warning system in order to save the inhabited communities from the disaster.

\section{Keywords}

Tsunami Modeling, TUNAMI N2, Nuclear Power Plants, Makran Subduction Zone

\section{Introduction}

The Sumatra 2004 tsunami was the most devastating ever in the history of tsunami hazard that had wiped out nearly 225,000 lives [1]. It has shaken the scientific community and compelled it to rethink about the hidden disaster locations. In the gulf of Arabian Sea (North-Western Indian Ocean), there is another historical record along Makran Subduction Zone (MSZ) where the largest instrumentally recorded tsunami was triggered by an earthquake $(M 8.1)$ on November 27, 1945 due to a thrust mechanism [2] [3]. It had severely damaged the nearby coastal cities and a total loss of 4000 lives was reported from these coasts [4]. According to the eyewitnesses, tsunami stroked the Gujarat coast like a fast high tide and the first wave of the tsunami approached (local time) on Salsette Island in Mumbai at 8.15 am with a run-up height of 2 meters; the tsunami spread out on to the south of Mumbai and caused 15 casualties [5]. The Arabian plate is deforming along the MSZ and subducting underneath the Eurasian plate at about $4 \mathrm{~cm} / \mathrm{yr}$. Recent research shows the staggering potential of MSZ to trigger a tsunamigenic earthquake of magnitude ranging from 8.7 to 9.2 [6] that can result a catastrophic impact in the coastal localities around the whole Arabian Sea in future. The Kalpakkam Nuclear Power Plant was affected by 2004 Sumatra tsunami and remained closed for few days [7]. Generally, the power plants in India are built in the low seismic regions. However, the power plants situated on the western coast may be affected by a future tsunami as they were designed before 2004 Sumatra event. Therefore, during the construction, they were not imparted that required resilience against tsunamis. Hence, a precise tsunami modeling scheme is of crucial importance for predicting the ramifications on these power plants due to the anticipated tsunamic event. In the present research, TUNAMI N2 model [7] is used to generate tsunami propagation maps, arrival time and run-up estimates to delineate the tsunami impacts on the four nuclear power plants location, i.e. Mithi-Virdi Nuclear Power Plant (MVPP), Gujarat; Tarapur Nuclear Power Plant (TNPP), Maharashtra; Jaitapur Nuclear Power Plant (JPP), Maharashtra and Kiaga Nuclear Power Plant (KPP), Karnataka.

\section{Methodology}

To simulate the tsunami, the code TUNAMI-N2 [8] [9] is used in the present 
study. It can estimate the water surface rise and velocities by the waves throughout the physical domain of the computational system. TUNAMI N2 has already been implemented for the tsunami simulation in the Atlantic and Pacific Oceans [10]. The eddy turbulence expressions are insignificant with respect to the bottom friction for the tsunami propagation in the shallow water. Tsunamis are generally computed by $2 \mathrm{D}$ hydrostatic models because the vertical acceleration related to the tsunami waves is less than the gravitational acceleration. The governing equations for tsunami simulation are stated as follow

$$
\begin{gathered}
\frac{\partial \eta}{\partial t}+\frac{\partial M}{\partial x}+\frac{\partial N}{\partial y}=0 \\
\frac{\partial M}{\partial t}+\frac{\partial}{\partial x}\left(\frac{M^{2}}{D}\right)+\frac{\partial}{\partial y}\left(\frac{M N}{D}\right)+g D \frac{\partial \eta}{\partial x}+\frac{\tau_{x}}{\Delta x}=A\left(\frac{\partial^{2} M}{\partial x^{2}}+\frac{\partial^{2} M}{\partial y^{2}}\right) \\
\frac{\partial M}{\partial t}+\frac{\partial}{\partial x}\left(\frac{M N}{D}\right)+\frac{\partial}{\partial y}\left(\frac{N^{2}}{D}\right)+g D \frac{\partial \eta}{\partial y}+\frac{\tau_{y}}{\rho}=A\left(\frac{\partial^{2} N}{\partial x^{2}}+\frac{\partial^{2} N}{\partial y^{2}}\right)
\end{gathered}
$$

where total water depth specified by $D$, the bottom frictions are $\tau_{\mathrm{x}}$ and $\tau_{\mathrm{y}}$ in the x- and y-directions, respectively. The constant $A$ is the horizontal eddy viscosity in space and the shear stress is ignored on a surface wave. $M$ and $N$ represent the discharge fluxes in the $\mathrm{x}$ - and $\mathrm{y}$-directions which is given by

$$
M=\int_{-h}^{n} u \mathrm{~d} z=u(h+\eta)=u D, \quad N=\int_{-h}^{n} v \mathrm{~d} z=v(h+\eta)=v D
$$

The bottom friction is usually stated as follows

$$
\frac{\tau_{x}}{\rho}=\frac{1}{2 g} \frac{f}{D^{2}} M \sqrt{M^{2}+N^{2}}, \frac{\tau_{y}}{\rho}=\frac{1}{2 g} \frac{f}{D^{2}} N \sqrt{M^{2}+N^{2}}
$$

The formulation depicts that the bottom friction has an inverse relation to the depth and it can get intensified with the fluxes. As a result, when the wave energy transmits in low-lying water regions, the tsunami energy dissipates rapidly. The Manning's roughness " $n$ " and friction coefficient " $f$ " can be defined by following relation

$$
n=\sqrt{\frac{f D^{1 / 3}}{2 g}}
$$

The value of $n$ is almost a constant when $D$ has a small and $f$ has a large value. Putting $M, N$, and the aforesaid values in Equation (2.1), (2.2), and (2.3), basic non-linear shallow water wave equations can be explained by

$$
\begin{gathered}
\frac{\partial \eta}{\partial t}+\frac{\partial M}{\partial x}+\frac{\partial N}{\partial y}=0 \\
\frac{\partial M}{\partial t}+\frac{\partial}{\partial x}\left(\frac{M^{2}}{D}\right)+\frac{\partial}{\partial y}\left(\frac{M N}{D}\right)+g D \frac{\partial \eta}{\partial x}+\frac{g n^{2}}{D^{7 / 3}} M \sqrt{M^{2}+N^{2}}=0 \\
\frac{\partial N}{\partial t}+\frac{\partial}{\partial x}\left(\frac{M N}{D}\right)+\frac{\partial}{\partial y}\left(\frac{N^{2}}{D}\right)+g D \frac{\partial \eta}{\partial y}+\frac{g n^{2}}{D^{7 / 3}} N \sqrt{M^{2}+N^{2}}=0
\end{gathered}
$$


The applied initial boundary condition is estimated using [11]. The free transmission as a boundary condition is applied at the open sea, and boundary condition on the land is supposed to be a perfect reflector. Since the water depth is less than the horizontal dimension of the tsunami at the earthquake location, the hydrodynamic effect is often ignored. In the present study, the frictional coefficient 0.025 is used. The tsunami modelers have used this code extensively to figure out the propagation, arrival times, and run-ups due the tsunami. A similar study using the TUNAMI N2 has been done on Andaman-Sumatra subduction zone [12]. [13] has shown the impacts of 2011 Tohoku tsunami on nuclear power plants using this code. Hence, this method is compatible for the other similar tsunami impacts on nuclear power plants. Once the outcomes are obtained using this method, the results are visualized in the form of propagation maps, directivity maps, arrival time map, and run-ups by writing MATLAB programme.

\section{Input Data}

For tsunami modeling, 1-min bathymetry data are used from General Bathymetric Chart of the Ocean (GEBCO, http://www.gebco.net/) as shown in Figure 1. In a recent study [14], it is suggested that eastern part of the MSZ (near the location of 1945 event) is more vulnerable to a future tsunami. Therefore, in the present study, we assume that tsunami will be triggered from the same location as was during the 1945 event (epicenter: $63.48^{\circ} \mathrm{E}, 25.15^{\circ} \mathrm{N}$ ). The source parameters are estimated using the formulation [15]. They are as follow: Fault length = $378 \mathrm{Km}$, Width $=180$, Depth $=15 \mathrm{Km}$, Strike $=255^{\circ}$, Dip $=7^{\circ}$, Rake $=90^{\circ}$, Slip $=11 \mathrm{~m}$.

\section{Results and Discussion}

The tsunami arrival times are calculated for the four nuclear power plants (Figure 1). It is observed from the modeling that the tsunami reaches at around Mithi-Virdi coast after 230 minutes, at Tarapur after 215 minutes, at Jaitapur after 210 minutes and at Kaiga after 225 minutes. It is observed that the tsunami reaches first along the Jaitapur than Tarapur despite the greater distance from the tsunami origin point. Tarapur nuclear power plant is situated $83 \mathrm{~km}$ away of Mumbai in north direction and Jaitapur nuclear power plant is situated in Ratnagiri district. Reference [16] also suggested that tsunami will reach Ratnagiri first before Mumbai due to variation in shelf-width. A few other reasons may include the directivity of the tsunami waves from the origin point and uneven sea floor that has the capacity to either slow down or speed up the tsunami waves (Figure 1). Figure 2 represents wave propagation model of a great Makran tsunami at different time steps (i.e. 0, 60, 120, 180, 240 and minutes) from left top to right bottom. Due to variations in bathymetry, the wave amplitude varies as waves are transmitted into the Arabian Sea. It can be noticed from the simulation that initially tsunami wave transfers rapidly in the Arabian Sea, and it slows 

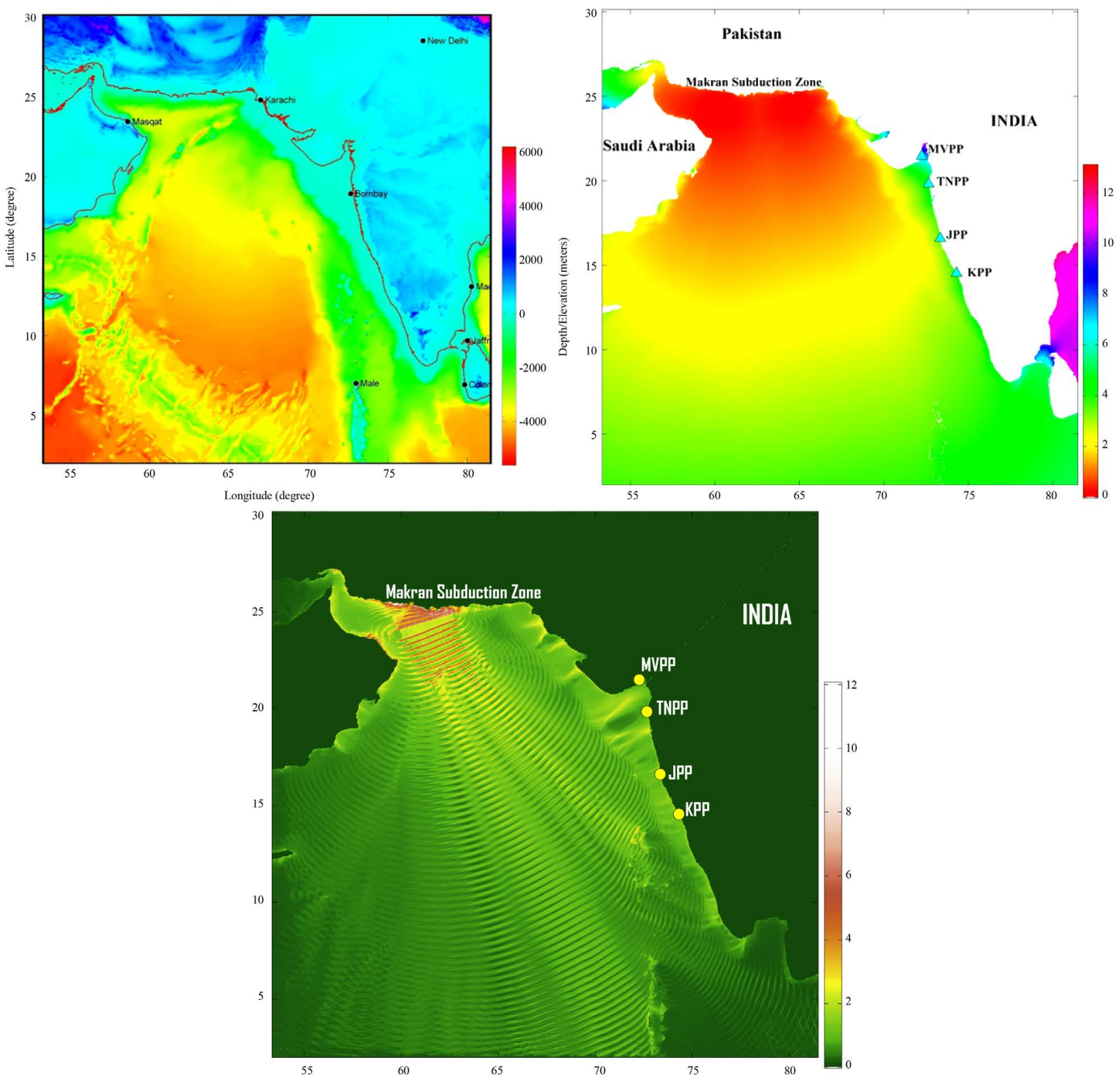

Figure 1. (Top left to bottom right) Screenshots of bathymetry map, tsunami travel time map, and directivity map.

down near the shallow coastal area of Gujarat. Further, it is observed that Owen Fracture Zone, Murray Ridge, Carlsberg Ridge and other topographies on the bottom of the Arabian Sea could affect the tsunami propagation, as their presence might amplify or dampen the wave transmission energy in the Arabian Sea. The tsunami run-up can be explained as a function of the coastline gradient, elevation of the area, living community configuration, infrastructure setup, etc. It is observed that run-up heights along the coast of Mithi-Virdi, Tarapur, Jaitapur and Kaiga nuclear power plants are $0.93 \mathrm{~m}, 2.12 \mathrm{~m}, 2.32 \mathrm{~m}$, and $2.15 \mathrm{~m}$, respectively (Figure 3, Table 1). Reference [17] also reported that the tsunami height was nearly $2 \mathrm{~m}$ around Mumbai due to 1945 event that further corroborates the present study. 

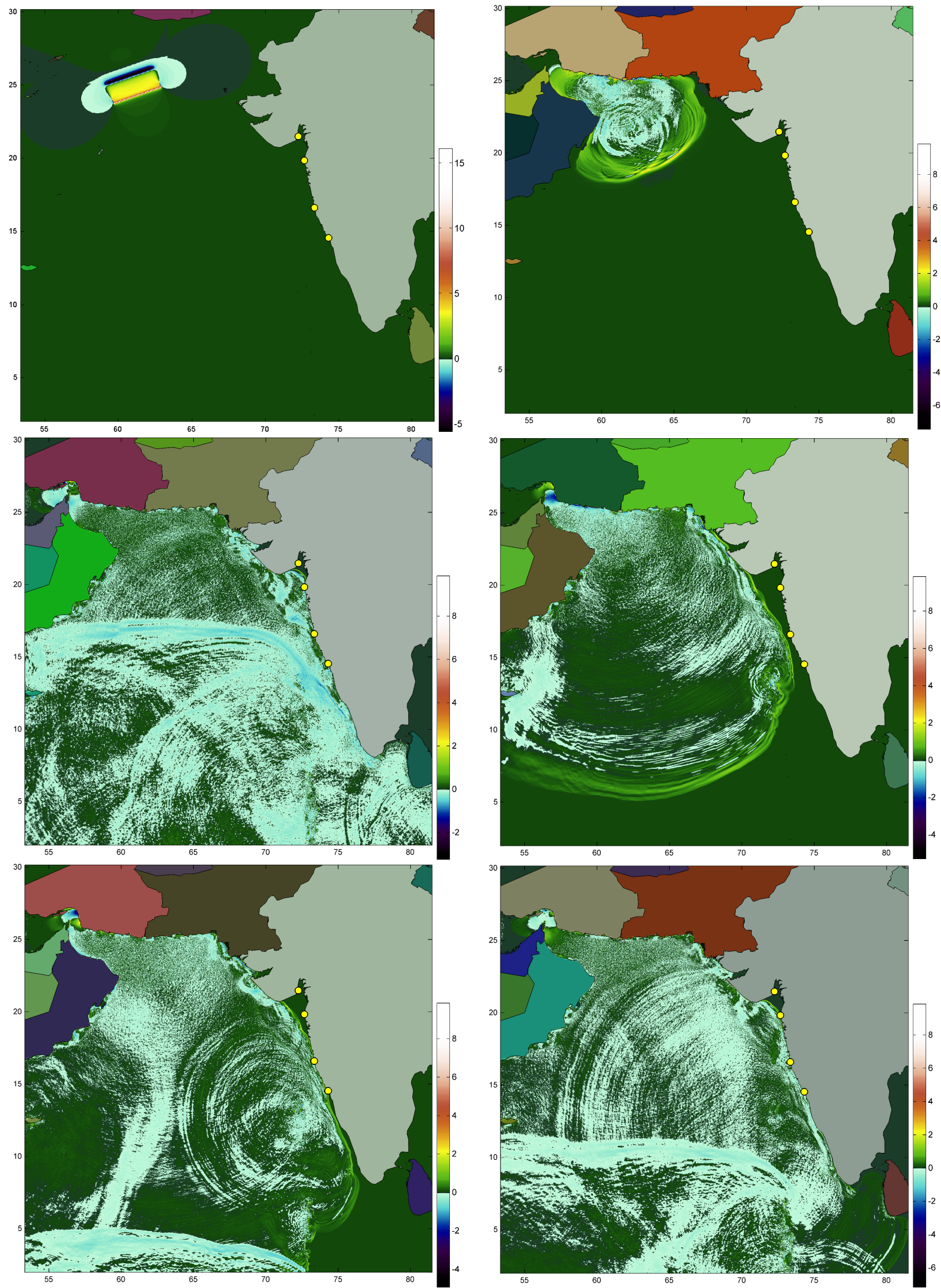


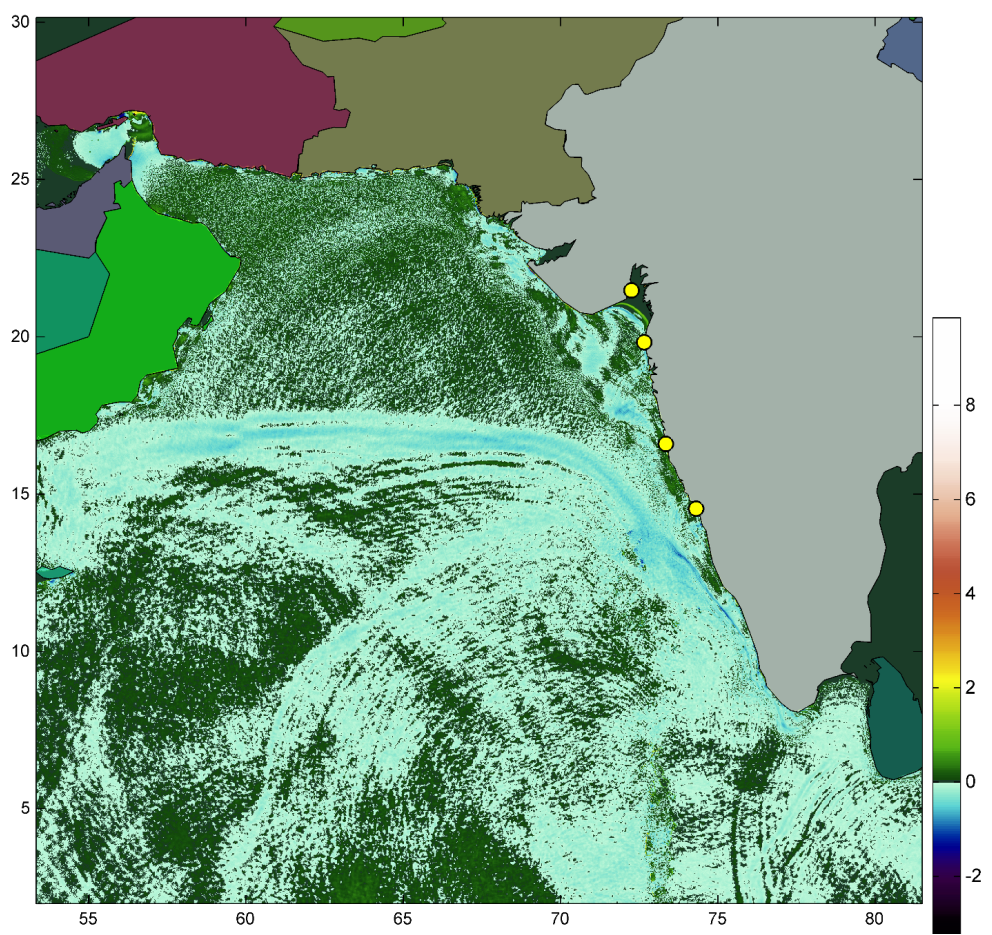

Figure 2. Tsunami propagation model in the Arabian sea due to the Makran induced tsunami by a great earthquake ( $M 9$ ). The screenshots (top left to bottom right) are showing tsunami propagation after 0, 60, 120, 180, 240, 300 and 360 minutes after the earthqauke.

Table 1. Run-up height at four nuclear power plants. The run-up is directly related to the tsunami directivity. The tsunami directivity is lowest at Mithi-Virdi as it is located on the southern coast of Gujarat, but highest for Jaitapur as it is exposed to the tsunami direct impacts. (Latitude and longitude for power plant locations are taken from Google Earth.)

\begin{tabular}{ccccc}
\hline Power Plant & Latitude $\left(^{\circ}\right)$ & Longitude $\left({ }^{\circ}\right)$ & Run-up $(\mathrm{m})$ & Arrival Time (hrs) \\
\hline Mithi-Virdi & 21.49 & 72.24 & 0.93 & 230 \\
Tarapur & 19.83 & 72.66 & 2.12 & 215 \\
Jaitapur & 16.99 & 73.35 & 2.32 & 210 \\
Kaiga & 14.67 & 74.30 & 2.15 & 225 \\
\hline
\end{tabular}

\section{Conclusion}

The nuclear power plants along the western coast of India are exposed to a Makran induced tsunami. Therefore, in the present study, we computed the tsunami arrival times and run-up heights for four power plants along the coastal location by a Great tsunamigenic earthquake ( $M$ 9). TUNAMI-N2 Program is used to model tsunami wave propagation and inundation, which is triggered by the movement of sea bottom due to earthquakes. The code assumes the linear-theory in deep sea and non-linear theory in shallow sea. To model tsunami waves, the code is developed based on finite-difference technique, using Leap-Frog scheme, which has the ability to model the tsunami with much more precision. The modeling results showed that the tsunami impacts might be highest for the Jaitapur coast in Maharashtra and least for the Mithi-Virdi along the 

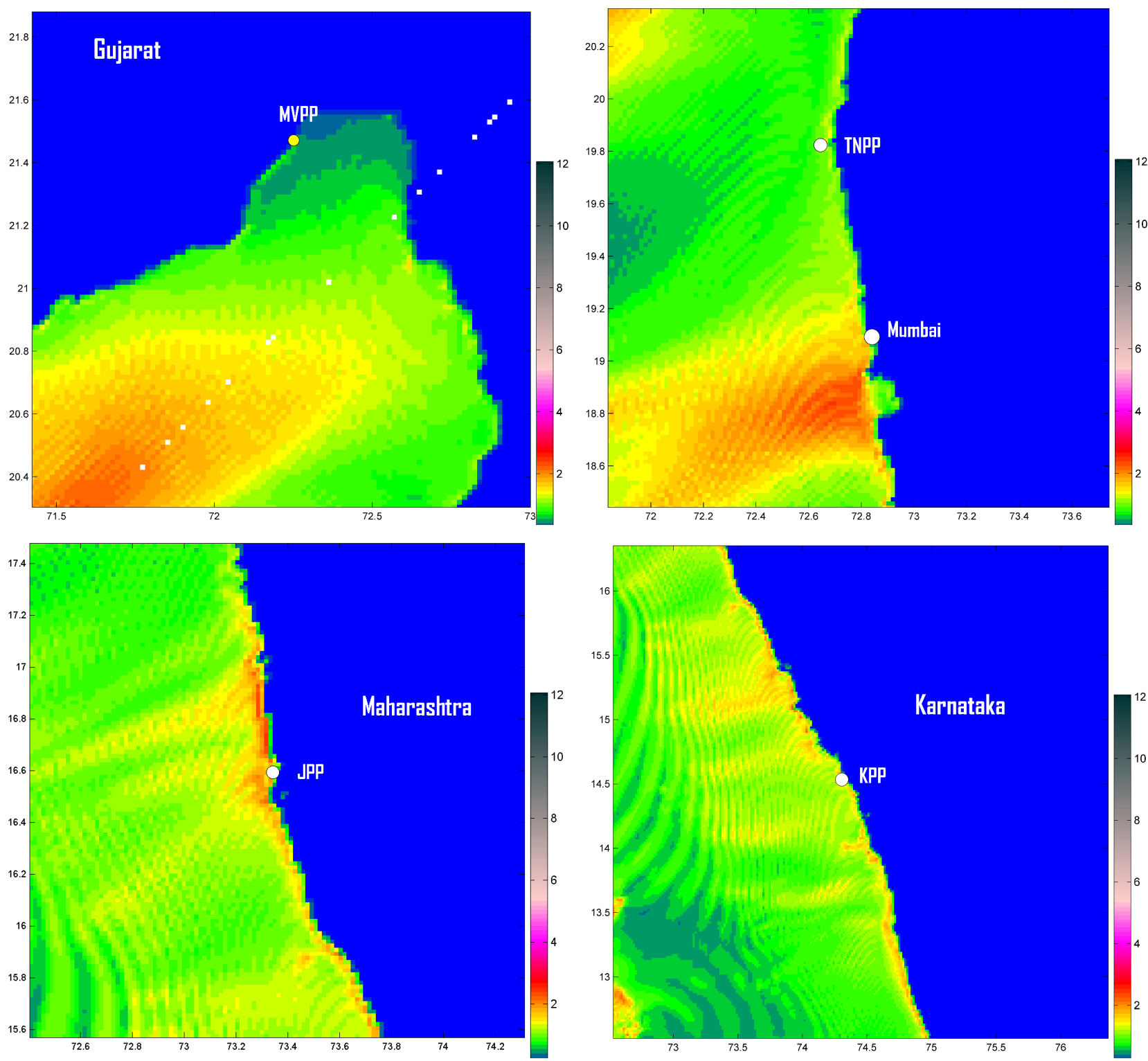

Figure 3. Displays the tsunami run-up heights along (from top left to bottom right) Mithi-Virdi, Tarapur, Jaitapur and Kaiga nuclear power plant. MVPP: Mithi-Virdi Power Plant; TNPP: Tarapur Nuclear Power Plant; JPP: Jaitapur Power Plant; KPP: Kaiga Power Plant.

southern coast of Gujarat. Tarapur and Kiaga coast in Maharashtra might also face quite an intense devastation. But, Jaitapur nuclear power plant is located 1 $\mathrm{Km}$ away from the sea with an altitude of $27 \mathrm{~m}$ that makes Jaitapur a safe location for the power plant. On the other hand, the continental shelf-width is extremely wide along the Tarapur, and the tsunami wave energy dampens as it enters in shallow-depth regions. So, flooding chances along the Tarapur is negligible. Moreover, the Kaiga power plant is also free from tsunami threat as it is situated $55 \mathrm{Km}$ away from the sea, but its coast might face some strong tsunami waves. The present study might help in adopting proper mitigation measures, evacuation planning and installing early warning system for the West Indian 
coastline.

\section{References}

[1] Geist, E., Titov, V. and Synolakis, C. (2006) Tsunami: Wave of Change. Scientific American, 294, 56-63. https://doi.org/10.1038/scientificamerican0106-56

[2] Byrne, D.E., Sykes, L.R. and Davis, D.M. (1992) Great Thrust Earthquakes and Aseismic Slip along the Plate Boundary of the Makran Subduction Zone. Journal of Geophysical Research, 97, 449-478. https://doi.org/10.1029/91JB02165

[3] Koppa, C., Fruehn, J., Flueh, E.R., Reichert, C., Kukowski, N., Bialas, J. and Klaeschen, D. (2000) Structure of the Makran Subduction Zone from Wide-Angle and Reflection Seismic Data. Tectonophysics, 329, 171-191. https://doi.org/10.1016/S0040-1951(00)00195-5

[4] Heck, N.H. (1947) List of Seismic Sea Waves. Bulletin of Seismological Society of America, 37, 269-286.

[5] Pararas-Carayannis, G., (2006) The Potential for Tsunami Generation along the Makran Subduction Zone in the Northern Arabian Sea. Case Study: The Earthquake and Tsunami of November 28, 1945. Science of Tsunami Hazard, 24, 358-384.

[6] Smith, G.L., McNeill, L.C., Wang, K., He, J. and Henstock, T.J. (2013) Thermal Structure and Megathrust Seismogenic Potential of the Makran Subduction Zone. Geophysical Research Letters, 40, 1528-1533. https://doi.org/10.1002/grl.50374

[7] Jin, S., Hong, S. and Imamura, F. (2006) 2004 Indian Ocean Tsunami on the Madras Nuclear Power Plant, India. Transactions of the Korean Nuclear Society Spring Meeting, Chuncheon, 25-26, May 2006.

[8] Gusiakov, V.K. (1978) Static Displacement on the Surface of an Elastic Space. III-Posed Problems of Mathematical Physics and Interpretation of Geophysical Data. The Computing Center of Soviet Academy of Sciences, VC SOAN SSSR, Novosibirsk, 23-51. (in Russian)

[9] Imamura, F. (1996) Review of Tsunami Simulation with a Finite Difference Method. In: Yeh, H., Liu, P. and Synolakis, C., Eds., Long-Wave Run-Up Models. World Scientific, 25-42.

[10] Titov, V.V. (1997) Numerical Modeling of Long Wave Runup. Ph.D Thesis, University of Southern California, Los Angeles, CA, 144.

[11] Mansinha, L. and Smylie, D.E. (1971) The Displacements Fields of Inclined Faults. Bulletin of the Seismological Society of America, 61, 1433-1440.

[12] Srivastava, et al. (2011) Would Makran Tsunami Would Skip Mumbai, India? No, It Would Reach 8 Minutes Later than Ratnagiri. Indian Journal of Geo-Marine Science, 40, 620-623.

[13] Dao, M.H., et al. (2013) Modelling of Tsunami-Like Wave Run-Up, Breaking and Impact on a Vertical Wall by SPH Method. Natural Hazards and Earth System Sciences, 13, 3457-3467. https://doi.org/10.5194/nhess-13-3457-2013

[14] Lin, Y.N., et al. (2015) High Interseismic Coupling in the Eastern Makran (Pakistan) Subduction Zone. Earth and Planetary Science Letters, 420, 116-126. https://doi.org/10.1016/j.epsl.2015.03.037

[15] Okada, Y. (1985) Surface Deformation Due to Shear and Tensile Faults in a Half-Space. Bulletin of the Seismological Society of America, 75, 1135-1154.

[16] Srivastava, K., Swaroopa, V., Srinagesh, D. and Dimri, V.P. (2007) Could the 12 Sept, 2007, Earthquake of Southern Sumatra, Indonesia, Have Generated a Large 
Tsunami Causing Damage to the East Coast of India? Current Science, 93, 1228-1229.

[17] Ambraseys, N.N. and Melville, C.P. (1982) A History of Persian Earthquakes. Cambridge University Press, Cambridge. 